The Feasibility of Wind and Solar Energy Application for Oil and Gas Offshore Platform

This content has been downloaded from IOPscience. Please scroll down to see the full text.

2015 IOP Conf. Ser.: Mater. Sci. Eng. 78012042

(http://iopscience.iop.org/1757-899X/78/1/012042)

View the table of contents for this issue, or go to the journal homepage for more

Download details:

IP Address: 134.7.93.129

This content was downloaded on 21/03/2017 at 07:17

Please note that terms and conditions apply.

You may also be interested in:

A method for measuring thermal radiation properties of semi-transparent materials

Y P Zhang, X S Ge and H L Huang

Effect of aerosols on performance of concentrator photovoltaics

Kei Nomura, Kenta Imai, Yasuyuki Ota et al.

A Dielectric Multilayer Filter for Combining Photovoltaics with a Stirling Engine for Improvement of the Efficiency of Solar Electricity Generation

Shou Chun-Hui, Luo Zhong-Yang, Wang Tao et al.

Shaped nonimaging Fresnel lenses

Ralf Leutz, Akio Suzuki, Atsushi Akisawa et al.

Characterization of the silicon nanopillar-surface filled and grafted with nanomaterials

Yuan He, Xiangchen Che and Long Que

Luminescence dynamics of Te doped CdS quantum dots at different doping levels

Wenzhi Wu, Hongan Ye and Xiulin Ruan

Photoelectrochemical water splitting on nanoporous GaN thin films for energy conversion under

visible light

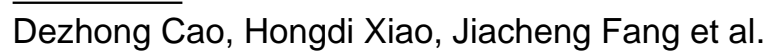

Modification of silver anode and cathode for a top-illuminated organic photovoltaic device

Chi-Feng Lin, Shun-Wei Liu, Wei-Feng Hsu et al.

Efficient Z-scheme charge separation in novel vertically aligned $\mathrm{ZnO} / \mathrm{CdSSe}$ nanotrees

Zhengxin Li, Jesus Nieto-Pescador, Alexander J Carson et al. 


\title{
The Feasibility of Wind and Solar Energy Application for Oil and Gas Offshore Platform
}

\author{
Y K Tiong, M A Zahari, S F Wong and S S Dol ${ }^{1}$ \\ Department of Mechanical Engineering, Curtin University \\ Sarawak Campus CDT 250, 98009 Miri, Sarawak, MALAYSIA
}

E-mail: sharulsham@curtin.edu.my

\begin{abstract}
Renewable energy is an energy which is freely available in nature such as winds and solar energy. It plays a critical role in greening the energy sector as these sources of energy produce little or no pollution to environment. This paper will focus on capability of renewable energy (wind and solar) in generating power for offshore application. Data of wind speeds and solar irradiation that are available around SHELL Sabah Water Platform for every 10 minutes, 24 hours a day, for a period of one year are provided by SHELL Sarawak Sdn. Bhd. The suitable wind turbine and photovoltaic panel that are able to give a high output and higher reliability during operation period are selected by using the tabulated data. The highest power output generated using single wind energy application is equal to $492 \mathrm{~kW}$ while for solar energy application is equal to $20 \mathrm{~kW}$. Using the calculated data, the feasibility of renewable energy is then determined based on the platform energy demand.
\end{abstract}

\section{Introduction}

Nowadays, most of the offshore platforms are operated by burning of fossil fuels to generate electricity. The gas turbines and diesel generators on most platforms are used to drive pumps and compressors on board, powered up by combustion of conventional fuels. Continuous burning of these conventional fuels will generate about $80 \%$ of the total $\mathrm{CO} 2$ and $\mathrm{NOx}$ emissions from offshore installations [1]. Thus, offshore platform are facing difficulties in term of operating their activities in an environmentally manner.

Currently, great efforts have been taken in greening the energy sector by shifting the usage of fossil fuels to renewable energy in order to minimize current rate of fossil fuel usage and their ensuing effects of climatic changes. Renewable energy such as wind energy, solar energy and ocean energy are highly focused in the feasibility test of replacing conventional fuels to operate an offshore oil and gas platform. Some of the offshore platform has already started to exploit a renewable energy sources to generate power supply to lessen consumption of fuels. For example, a new offshore platform in the Southern North Sea as shown in figure 1 is operated by using their own energy generated through solar panels and wind turbines [2].

1 To whom any correspondence should be addressed. 


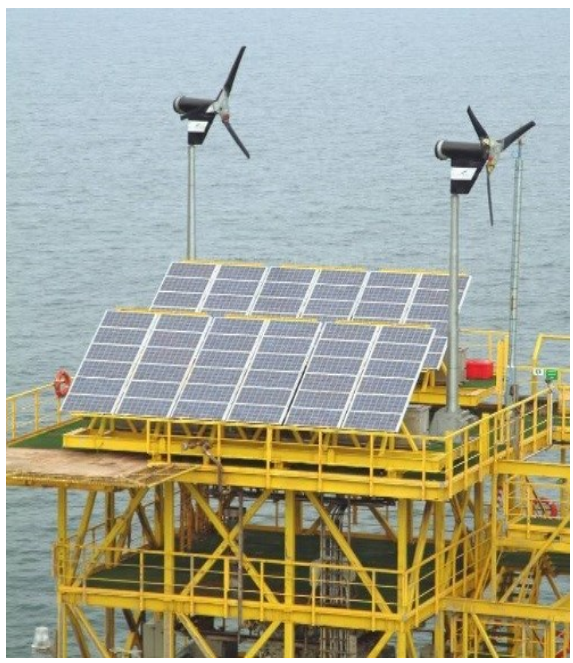

Figure 1. Wind turbines and solar panels on offshore platform [2]

Wind and solar seems like ideal alternative sources of energy as it can provide an infinite amount of clean energy for offshore application. This paper will focus on the capability of renewable energy available around the offshore platform in order to determine the possibility of such utilization to meet the demand needed for these platform activities. Out of all renewable energies available these days, wind energy and solar energy are highly focused in this feasibility test since data collected predicted a rather promising result. Electrical power consumption of a platform is within the range from $10 \mathrm{MW}$ to $50 \mathrm{MW}$, while the power consumption for smaller unmanned varies from $6 \mathrm{MW}$ to $7 \mathrm{MW}$ [1]. The targeted platform for this study is carried out at SHELL Malaysia Oil and Gas Sabah Water Platform, with the rated power consumption is approximately $10 \mathrm{MW}$. Based on the data collected from the targeted platform, the rated power output are determined in order to meet the demand of power consumption of this platform.

\section{Literature review}

\subsection{Wind energy}

In this feasibility study, SIEMENS SWT-4.0-120 is selected due to its suitable cut-in speed as low as $2.9 \mathrm{~m} / \mathrm{s}$. The wind turbine selected is a direct drive horizontal axis wind turbine, with the latest patented Quantum Blade technology used by Siemens, and able to generate rated power output as high as $4 \mathrm{MW}$ with rated wind speed of $13 \mathrm{~m} / \mathrm{s}$ [3].

In order to determine the rated power output, $P_{\text {rated }}$ for specific month, equation (1) is used. Where, $A_{r}$ is the swept area of the rotor; PD is the power density by the wind; $\eta$ is the efficiency of the selected wind turbine stated by the manufacturer [4].

$$
P_{\text {rated }}=A_{r} \times \mathrm{PD} \times \eta
$$

The swept area, $A_{r}$ by the rotor of wind turbine can be determined by using equation (2) where, $D$ is the diameter of the rotor for the selected wind turbine.

$$
A_{r}=\pi \times\left(\frac{D}{2}\right)^{2}
$$


The power density, PD of the wind is determined by the equation (3) where, $P_{\text {air }}$ is the air density at $50 \mathrm{~m}$ above sea level and ${ }^{v}$ is the wind speed.

$$
\mathrm{PD}=\frac{1}{2} \times \rho_{\text {air }} \times\left(\frac{v^{3}}{1000}\right)
$$

For Siemens SWT-4.0-120, the efficiency for the selected wind turbine is $32 \%$, giving the value of $\eta$ is equal to $0.32[3]$.

\subsection{Solar energy}

For the solar energy, the selected photovoltaic panel used for this feasibility test is LG290 N1C-G3 MonoX, with the panel area of $1.64 \mathrm{~m}^{2}$ and peak power output of $290 \mathrm{~W}$ [5]. The power output for photovoltaic panel can be determined via the equation (4):

$$
P=A_{p} \times r \times H \times \mathrm{PR}
$$

where, $A_{p}=$ area of solar panel in $\mathrm{m}^{2}, r=$ solar panel yield $(\%), H=$ average solar radiation on panels $\left(\mathrm{W} / \mathrm{m}^{2}\right)$ and $\mathrm{PR}=$ Performance ratio.

Previous studies suggested that the performance ratio is set as 0.75 as default when solar panel is tilted at $45^{\circ}$ of the direction of irradiation [6]. This value varies depending on the shadings present around the solar panel, as well as the cleanliness of the solar panel itself which is referring to the dust accumulation on solar panel.

Solar panel yield, $r$ can be determined by the equation (5) where, $\mathrm{PE}$ is the electrical power of solar module selected; $A_{p}$ is the area of the solar module.

$$
\text { Solar Panel Yield, } r(\%)=\frac{P E}{10 A_{p}}
$$

\section{Data}

\subsection{Wind energy}

In this research, wind speed data surrounding the SHELL Sabah Water Platform is provided by Sarawak SHELL Bhd. With the tabulated data, the average monthly wind speed hitting around the platform $50 \mathrm{~m}$ above sea level are plotted as in figure 2 .

Based on figure 2, the wind speeds around the SHELL Sabah Water Platform are within a range of $3.22 \mathrm{~m} / \mathrm{s}$ to $6.07 \mathrm{~m} / \mathrm{s}$. A sample calculation to determine the rated power output is shown using the average wind speed on January $(6.07 \mathrm{~m} / \mathrm{s})$. The wind turbine specification and wind parameter are listed in table 1.

The power output for January is calculated using the equations discussed before. The swept area by the rotor of wind turbine is given by equation (2):

$$
A_{r}=\pi \times\left(\frac{D}{2}\right)^{2}=\pi \times\left(\frac{120}{2}\right)^{2}=11310 \mathrm{~m}^{2}
$$




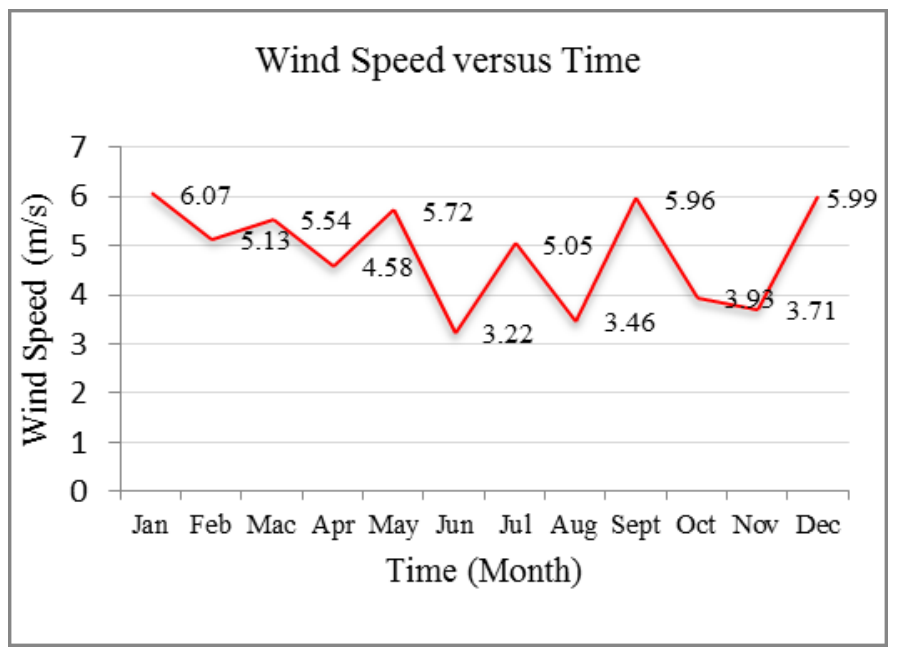

Figure 2. Average Wind Speed collected on SHELL Sabah Water Platform in 2008

Table 1. Wind turbine and wind parameters

\begin{tabular}{lc}
\hline \multicolumn{2}{c}{ Wind Turbines (SIEMENS SWT-4.0-120) } \\
\hline Rotor diameter, $D[\mathrm{~m}]$ & 120 \\
Blade length, $L[\mathrm{~m}]$ & 58.5 \\
Efficiency, $\boldsymbol{\eta}[\%]$ & 32 \\
\hline & Wind \\
\hline Air density, $\boldsymbol{\rho}_{\text {air }}\left[\mathrm{kg} / \mathrm{m}^{3}\right]$ & 1.225 at $50 \mathrm{~m}$ above sea level
\end{tabular}

The power density, PD by the wind onto the wind turbine is determined by the equation (3):

$$
\mathrm{PD}=\frac{1}{2} \times \rho \times v^{3}=0.5 \times 1.225 \times 6.07^{3}=137 \mathrm{~kg} / \mathrm{s}^{3}
$$
(1):

Then, the power output for specific wind turbine for January can be determined via the equation

$$
P_{\text {rated }}=A_{r} \times \mathrm{PD} \times \eta=11310 \times 137 \times 0.32=495830 \mathrm{~W}=495 \mathrm{~kW}
$$

\subsection{Solar energy}

The solar irradiation available in the surrounding of SHELL Sabah Water Platform is provided by Sarawak SHELL Bhd. With the tabulated data, the average monthly solar irradiation hitting around the platform are plotted as in figure 3 . 


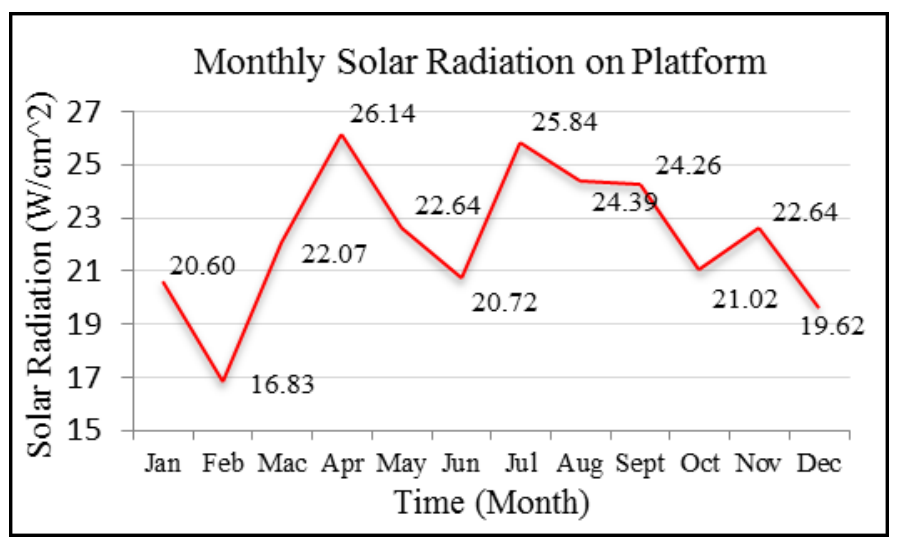

Figure 3. Average monthly solar radiation on SHELL Sabah water platform in 2008.

However, as the energy based on solar is dependent on the availability of the sun, additional graph is plotted based on daily solar irradiation to determine the peak hour of solar irradiation. With the collected data, the average daily solar irradiations hitting around the platform on are plotted as in figure 4.

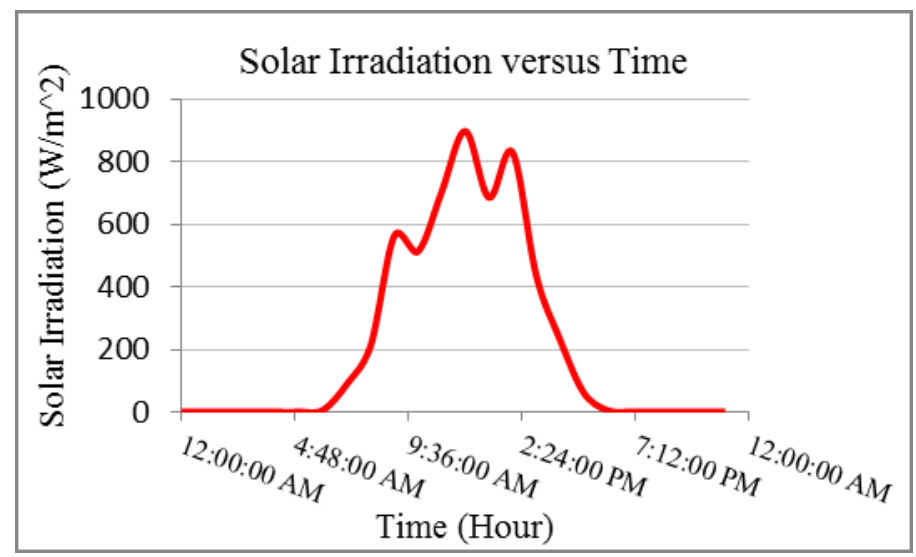

Figure 4. Daily solar irradiation peak hour on SHELL Sabah water platform.

Based on figure 3 and 4, the solar irradiation on the SHELL Sabah water platform varies within a range of $16.83 \mathrm{~W} / \mathrm{cm}^{2}$ to $26.14 \mathrm{~W} / \mathrm{cm}^{2}$ with the peak hour starting from 6 am to $6 \mathrm{pm}$. A sample calculation to determine the rated power output is shown using the average solar irradiation collected on April $\left(26.14 \mathrm{~W} / \mathrm{cm}^{2}\right)$. The selected photovoltaic panel used for this feasibility test is LG290 N1CG3 MonoX, with the panel area of $1.64 \mathrm{~m}^{2}$ and peak power output of $290 \mathrm{~W}$ [5]. While its performance ratio is set as default which is 0.75 based on the previous study [6]. The power output for April is calculated using the equations discussed before. Solar panel yield, $r$ can be calculated using equation (5):

$$
r(\%)=\frac{\mathrm{PE}}{10 A_{p}}=\frac{290}{10(1.64)}=17.68 \%
$$

The average solar irradiation collected in April is converted from $26.14 \mathrm{~W} / \mathrm{cm}^{2}$ to $94.10 \mathrm{kWh} / \mathrm{m}^{2}$. Then, the power output for photovoltaic panel can be calculated via the equation (4): 


$$
\begin{aligned}
P_{\text {rated }} & =A_{p} \times r \times H \times \mathrm{PR} \\
& =1.64 \times 0.1768 \times 94.1 \times 0.75=20 \mathrm{kWh}
\end{aligned}
$$

\section{Result and discussion}

The rated power output calculated for each month based on selected wind turbine for wind energy application are plotted as shown in Figure 5.

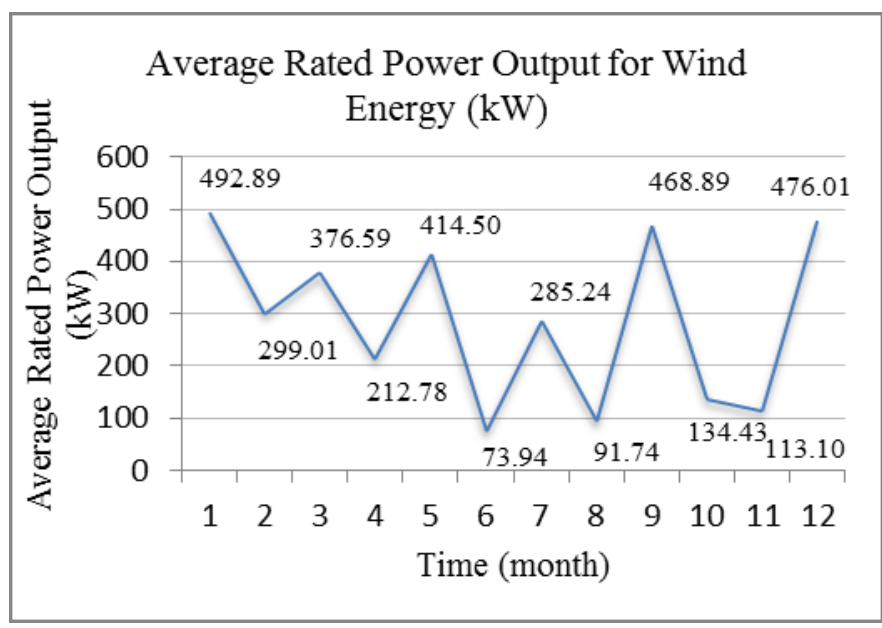

Figure 5. Monthly average rated power output for SIEMENS SWT4.0-120

Based on the figure 5, the monthly average rated power output generated by selected wind turbine SIEMENS SWT4.0-120 varies between the ranges of $73.94 \mathrm{~kW}$ to $492.89 \mathrm{~kW}$. The highest power output was generated in January while the lowest month of power generated by this turbine was in Jun.

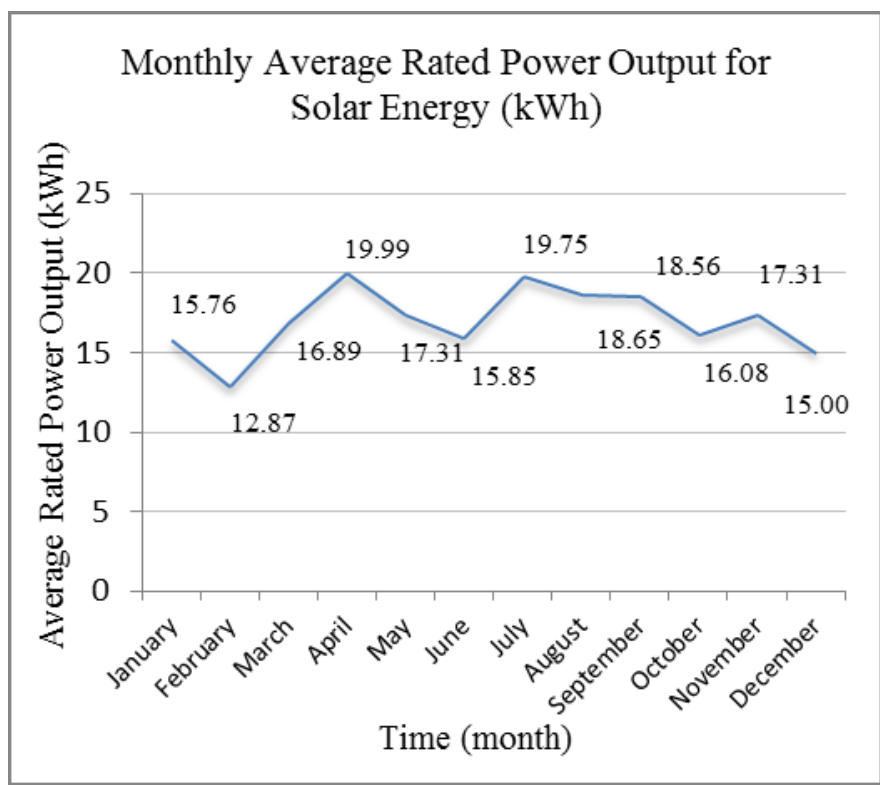

Figure 6. Monthly average rated power output for LG290 NIC-G3 MonoX 


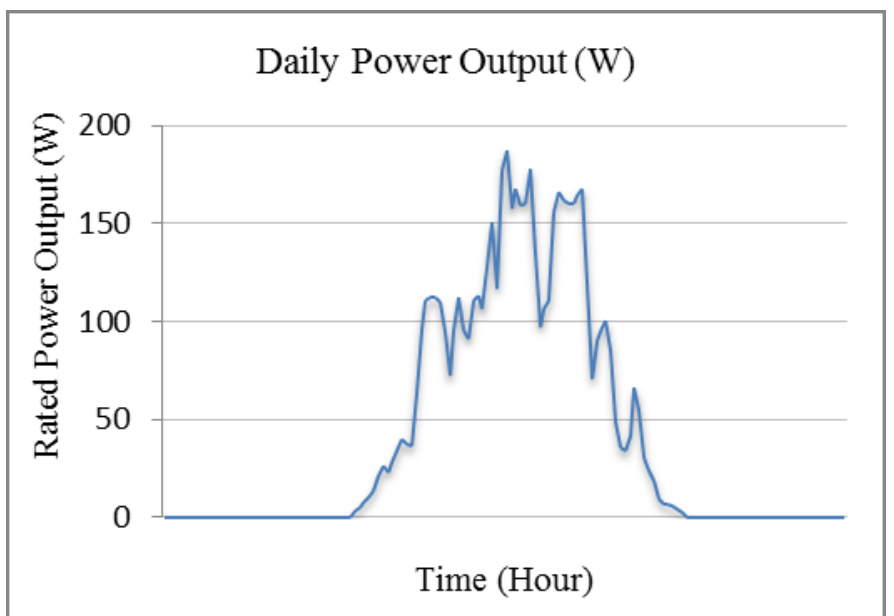

Figure 7. Daily average rated power output for LG290 NIC-G3 Monox

Based on the figure 6, the monthly average rated power output generated by solar panel LG290 NIC-G3 MonoX varies between the ranges of $12.87 \mathrm{kWh}$ to $19.99 \mathrm{kWh}$. The poorest month of solar irradiation falls on February with the power output generated $12.87 \mathrm{kWh}$ while the highest month of solar irradiation falls in April with the power output generated $19.99 \mathrm{kWh}$.

Based on daily power output in figure 7, at time between 12:00 a.m. and 6:00 a.m. as well as between 6:00 p.m. up till the next morning, the solar irradiation recorded is zero, indicating that the system has its downtime during this period of time. This is due to the availability of the sun [7]. The peak hour of daily solar irradiation falls at time between 11 a.m. to 3 p.m.

Based on the results discussed before, these wind turbine and solar panel can be installed in multiple units to form an array system in order to provide sufficient power supply to the selected offshore platform (figure 8). In order to accommodate the rated power output of $10 \mathrm{MW}$, the solar irradiation investigated should be from the poorest out of all months and days of all data collected to form an array. Moreover, an integrated system should be considered using both of these wind turbine and solar panel applications [9]. This is due to the complementary power output generated by these two forms of energy under seasonal variant in weather conditions. The solar panel plays a major role in generate highest power output in the summer months when the output from the wind turbine is at the lowest and vice versa during the monsoon season.

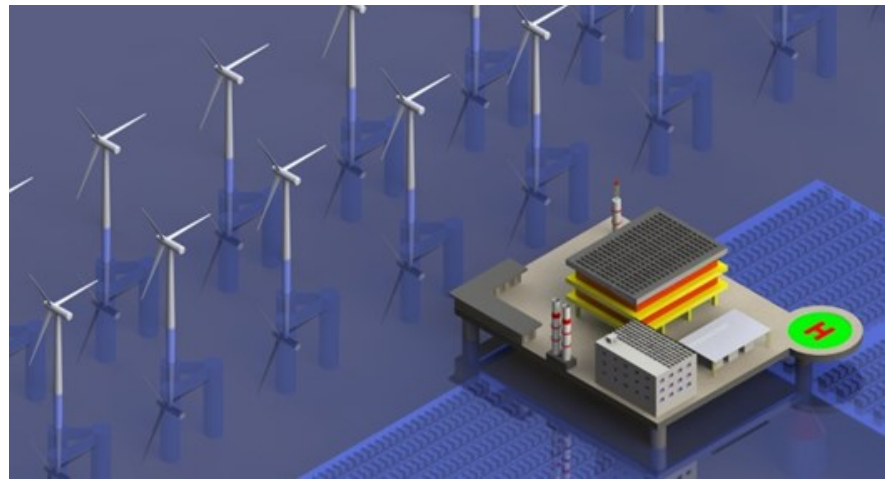

Figure 8. Multiple units of wind turbines and solar panels installed on offshore platform (conceptual design from [8]) 


\section{Conclusion}

The solar and wind energy application in generating energy is a viable solution of the current energy extraction problem for offshore application. In this paper, it showed that the highest power output generated for wind energy application is equal to $492 \mathrm{~kW}$ while for solar energy application power generated is equal to $20 \mathrm{~kW}$. As a single unit of solar or wind turbine system is insufficient in order to provide power supply to offshore platform application, these applications can be installed in multiple units in order to generate sufficient power supply. Both of these systems can also be integrated to each other due to their different capabilities in generated power output based on weathers and climates condition.

$\begin{array}{cc} & \text { Nomenclature } \\ P_{\text {rated }} & \text { Rated Power Output, W } \\ P & \text { Peak Power Output, W } \\ P D & \text { Power Density, W/m } \mathrm{m}^{2} \\ D & \text { Diameter of Rotor, } \mathrm{m} \\ L & \text { Blade length of Rotor, } \mathrm{m} \\ r & \text { Solar Panel Yield, } \% \\ H & \text { Average Solar Radiation on Panel, } \mathrm{kWh} / \mathrm{m}^{2} \\ P R & \text { Performance Ratio } \\ P E & \text { Electrical Power of Solar Module, W } \\ \eta & \text { Efficiency, } \% \\ A_{r} & \text { Swept Area of Rotor, } \mathrm{m}^{2} \\ A_{p} & \text { Area of Solar Panel, } \mathrm{m}^{2} \\ v & \text { Wind Velocity, } \mathrm{m} / \mathrm{s} \\ \rho_{\text {air }} & \text { Density of air above sea level, } \mathrm{kg} / \mathrm{m}^{3}\end{array}$

I.

\section{Acknowledgement}

The current speed and solar irradiation data on the SHELL Sabah Water Platform are provided by SHELL Sarawak Sdn. Bhd. and dated back in year 2008. 


\section{References}

[1] He W, Uhlen K, Hadiya M, Chen Z, Shi G and Rio E 2013 Case study of integrating an offshore wind farm with offshore oil and gas platforms and with onshore electrical grid Journal of Renewable Energy 1-10

[2] Rosebro J 2006 Fossil-fuel platform runs on renewable energy http://www.greencarcongress.com/2006/04/fossilfuel_plat.html

[3] Siemens 2014 Siemens 4.0MW offshore wind turbine http://www.energy.siemens.com/

[4] NPower nd Wind turbine power calculations The Royal Academy of Engineering

[5] Tecnospot 2013 MonoX Neon LG290NiC-G3 http://www.lg.com/uk/solar

[6] Hanid M, Ramzan M, Rahman M, Khan M, Amin M and Amir M 2012 Studying power output of PV solar panels at different temperatures and tilt angles ISESCO Journal Science and Technology 8 9-12

[7] Goffman E 2008 Why Not the Sun? Advantages of and Problems with Solar Energy Journal of ProQuest Discovery Guides

[8] Tiong Y K 2013 The renewable energy application for oil and gas offshore platform Thesis (B.ME.) Curtin University Malaysia.

[9] Zahari M A and Dol S S 2014 Application of vortex induced vibration energy generation technologies to the offshore oil and gas platform: The preliminary study International Journal of World Academy of Science, Engineering and Technology 8(7) 1331-34 